\title{
Developing the NIS solid density hydrostatic weighing system up to $20 \mathrm{~kg}$
}

\author{
Mohamed Hamdy $^{1, *}$, Mohamed A. Bayoumi ${ }^{2}$, Ali E. Abuelezz ${ }^{3}$, and Alaaeldin A. Eltawil ${ }^{1}$ \\ ${ }^{1}$ National Institute of Standards, Mass, Density and Pressure Laboratory, Giza, Egypt \\ 2 Al-Azhar University, Faculty of Engineering, Department of Mechanical Engineering, Cairo, Egypt \\ ${ }^{3}$ National Institute of Standards, Force \& Material Metrology Laboratory, Giza, Egypt
}

Received: 3 February 2020 / Accepted: 24 September 2020

\begin{abstract}
This paper presents a developed design and construction to improve the performance and increasing the density measuring capability of the previous Hydrostatic Weighing Apparatus (HWA-NIS) at the National Institute of Standards (NIS) up to $20 \mathrm{~kg}$. The previous (HWA-NIS) has been constructed up to $10 \mathrm{~kg}$ on 2014. The 2-Positions mass handler in the previous (HWA) was developed with 4-Positions pentagon shape to be able to make handling for individual masses in a group at once, when transferring the traceability from the primary standard "the Silicon Sphere" to the standard masses in the density scale weighing process. The weighing pan in the previous (HWA) was developed with four suspension wires with a diameter of $0.3 \mathrm{~mm}$ each, leads to reduce the surface tension affect on the measurement uncertainty by factor four times. The density of the standard masses in the range from $2 \mathrm{~kg}$ up to $20 \mathrm{~kg}$ were measured with an improved expanded uncertainty from $0.150 \mathrm{~kg} / \mathrm{m}^{3}$ to $0.078 \mathrm{~kg} / \mathrm{m}^{3}$ respectively due to reducing the effect of surface tension via the developed design of the weighing pan.
\end{abstract}

Keywords: Mass metrology / masses / volume and density / hydrostatic weighing apparatus / solid density uncertainty

\section{Introduction}

Density determination is needful for accurate determination of the mass. It is essential for the National Metrology Institutes (NMIs), accredited calibration laboratories. This is reflected in the International Organization of Legal Metrology (OIML) Standard OIML R111 [1] for a mass of $1 \mathrm{~kg} \mathrm{E}_{1}$, which gives a tolerance in the mass of only $500 \mu \mathrm{g}$. Such accuracy cannot be reached in the mass determination unless an accurate determination for the density of the used masses then carrying out air buoyancy correction associated with each mass measurement. The mass calculations of the standards being compared involve the volumes which are generally determined by hydrostatic weighing [2]. In reference to OIML R111 recommendation, it is stated that the certificate for the highest class $\mathrm{E}_{1}$ mass should mention the density or volume of each mass. The hydrostatic weighing method is based on Archimedes's principle [3] states that the upward buoyant force that is exerted on a body immersed in a fluid, whether fully or partially submerged, is equal to the weight of the fluid that the body displaces. Thiesen [4], in 1886, who is the first

\footnotetext{
* Corresponding author: eng.mohammedhamdi@yahoo.com
}

person proposed an idea to immerse object in a fluid in order to determine its volume. Such idea was congealed since there was no suitable approach of applying the idea. In 1967, Bowman and Schonover [5] from NIST formerly NBS, applied the idea of submerged the object effectively using a single-pan balance to determine its density. The national metrology institute of Switzerland (METAS) has established a hydrostatic weighing device to determine the density of the masses in grade of $\mathrm{E}_{1}$ according to OIML $\mathrm{R}$ 111-1: 2004 [1] concluded uncertainties from $0.1 \mathrm{~kg} / \mathrm{m}^{3}$ to $0.3 \mathrm{~kg} / \mathrm{m}^{3}$ for the masses from $2 \mathrm{~kg}$ to $10 \mathrm{~kg}$ [6] respectively. Buchner from BEV - Austria has designed and constructed a system for measuring the density by hydrostatic weighing for $\mathrm{E}_{1}$ masses in the range from $1 \mathrm{~kg}$ to $50 \mathrm{~kg}$ as discussed in [7] where the system functionality and measurement procedures were presented. The national metrology institute of Korea (KRISS) established a Hydrostatic Weighing Apparatus (HWA) to determine the density of masses ranging between $2 \mathrm{~kg}$ to $20 \mathrm{~kg}$ with associated uncertainties from $0.65 \mathrm{~kg} / \mathrm{m}^{3}$ to $0.87 \mathrm{~kg} / \mathrm{m}^{3}$ were reached [8].

In the year 2014, the NIS designed and constructed the Hydrostatic Weighing Apparatus (HWA-NIS) which could measure the density of standard masses ranging from $2 \mathrm{~kg}$ up to $10 \mathrm{~kg}$ based on the method $\mathrm{A}_{2}$ in OIML R111 
recommendation with an expanded uncertainty from $1.0 \mathrm{~kg} / \mathrm{m}^{3}$ to $1.4 \mathrm{~kg} / \mathrm{m}^{3}$ [9]. However, method $\mathrm{A}_{2}$ in OIML R111, 2004 uncertainty down to $0.1 \mathrm{~kg} / \mathrm{m}^{3}$ can be reached [1]. The (HWA-NIS) includes a weighing pan suspended underside the electronic digital balance with a rod of $6 \mathrm{~mm}$ diameter including a suspension wire with $4 \mathrm{~mm}$ diameter at the region of the surface tension effect. The suspension wire diameter can affect the surface tension around the $4 \mathrm{~mm}$ diameter at the time of weighing the standard and the under test mass in the distilled water by a large value. It should be noted that, the grated effect for a wire of $1 \mathrm{~mm}$ diameter will be $23 \mathrm{mg}$ [1]. Hence this weighing pan suspension wire was affected with $92 \mathrm{mg}$ standard uncertainty. The weighing pan was designed to carry a mass with a maximum capacity of $10 \mathrm{~kg}$ and theoretically to $20 \mathrm{~kg}$ [10] but still its suspension wire diameter of $4 \mathrm{~mm}$ which gives a large surface tension uncertainty source effect by about $80 \%$ of the total expanded uncertainty.

The mass handler of the (HWA-NIS) was designed with two positions, by such design it was not possible to handle the group of individual masses at once in the process of the density scale when it used to transfer the traceability from the primary standard "the Silicon Sphere" to the standard masses. Finally, the density of the $20 \mathrm{~kg}$ masses still measured at NIS using the method D in OIML R111 with an uncertainty in the order of $\pm 15 \mathrm{~kg} / \mathrm{m}^{3}$ [1].

To get rid of all these problems, this work develops and improves the (HWA-NIS) to be able to manually and automatically handle and measure the density of up to four masses of any shape ranging from $2 \mathrm{~kg}$ up to $20 \mathrm{~kg}$ with a standard uncertainty covers the OIML objective [1]. The development includes design and construction of a new alternative hydrostatic weighing parts, includes innovative design for a weighing pan able to carry masses up to $20 \mathrm{~kg}$ with four suspension wires with diameters of $0.3 \mathrm{~mm}$ for each one at the region of the intersection the distilled water surface with the diameter of these wires at the time of weighing in the distilled water to reduce the large uncertainty value due to surface tension effect and to be able to reach accepted standard uncertainty covers the requirements of OIML R111 for this method. The innovative design for the 4-positions mass handler can carry four masses with a maximum capacity of $20 \mathrm{~kg}$ for each mass. Also, each position was designed with a pentagonal shape to be able to carry groups of individual masses against one equivalent mass at once at the time of the density scale weighing process. The stress and deformation of the developed parts were checked using 3D Finite Element Analysis (FEA) [11] Solid Works software.

\section{The Developed Hydrostatic Weighing System (DHWS-NIS)}

The NIS developed Hydrostatic Weighing System (DHWSNIS) up to $20 \mathrm{~kg}$ was an obligatory a complement instead of the $10 \mathrm{~kg}$ NIS Hydrostatic Weighing Apparatus (HWANIS) that has been designed and constructed by NIS in the year 2014 [9]. The developed (DHWS-NIS) can be used for measuring masses density ranging from $2 \mathrm{~kg}$ up to $20 \mathrm{~kg}$ based on the hydrostatic weighing.

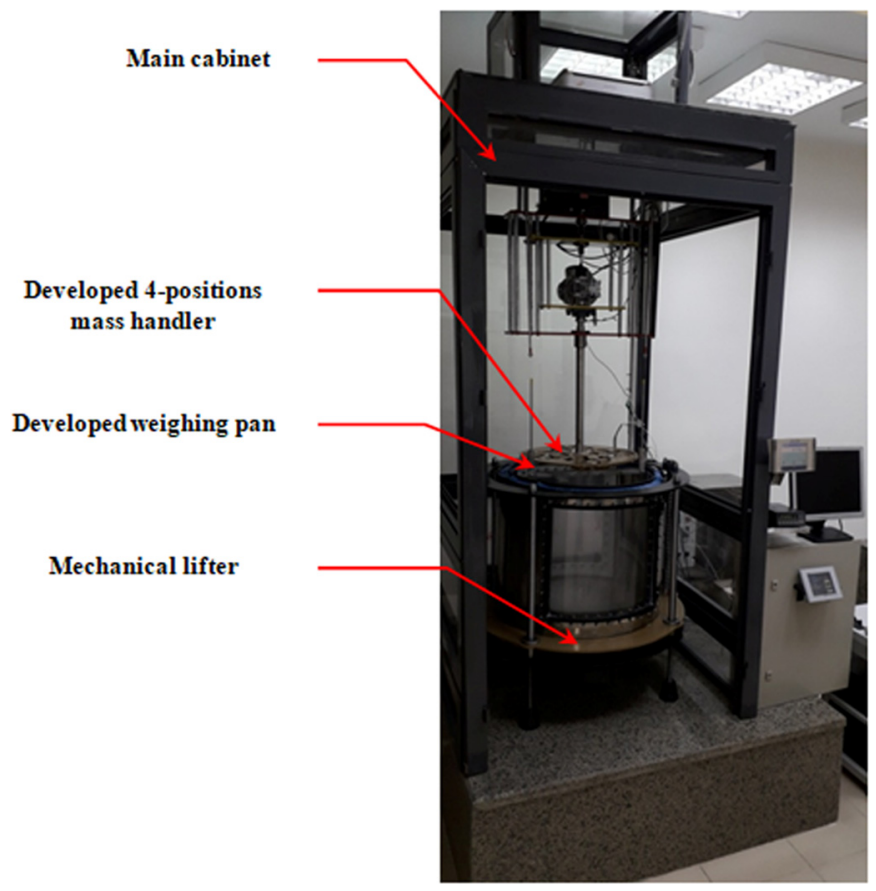

Fig. 1. A photograph for the (DHWS-NIS) on its final form.

The NIS developed (DHWS-NIS) shown in Figure 1 consisting of four main parts namely; (1) the main cabinet carries electronic digital comparator balance of a capacity $26 \mathrm{~kg}$ and readability of $1 \mathrm{mg}$. (2) The 4-positions mass handler is used for loading and unloading up to four standards including under test masses during the hydrostatic weighing process. (3) The developed weighing pan suspended underside of the electronic digital balance and is used for weighing the standard and under test masses below the reference liquid surface. (4) The mechanical lifter carries a water bath contains 260 liters of the distilled water in which the standard and under test masses are to be immersed during the hydrostatic weighing process. The temperature of the water bath is controlled to be within $\pm 0.01^{\circ} \mathrm{C}$.

The (DHWS-NIS) contains a system for ambient condition measurements. This system is consisting of atmospheric pressure measuring instrument with a readability of $0.1 \mathrm{~Pa}$ and thermo-hygrometer for measuring the ambient temperature with readability of $0.001^{\circ} \mathrm{C}$ and ambient relative humidity with readability of $0.01 \%$ [12] both are needed for air density calculations [13]. A PT-100 thermometer with a resolution of $0.001^{\circ} \mathrm{C}$ [12] is kept immersed in the distilled water and closed to the weighing pan to evaluate the temperature gradient of the distilled water temperature [14].

\section{Developed parts for the hydrostatic weighing System}

\subsection{The developed weighing pan}

The developed weighing pan is suspended underside the electronic digital balance by stainless steel rod of $6 \mathrm{~mm}$ diameter. The weighing pan was constructed with two 


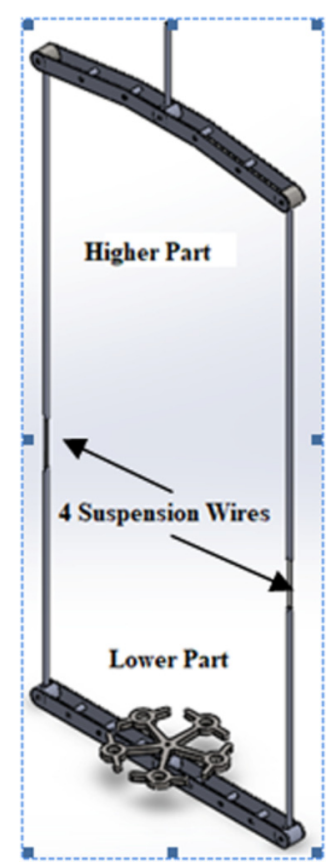

Fig. 2. The developed weighing pan.

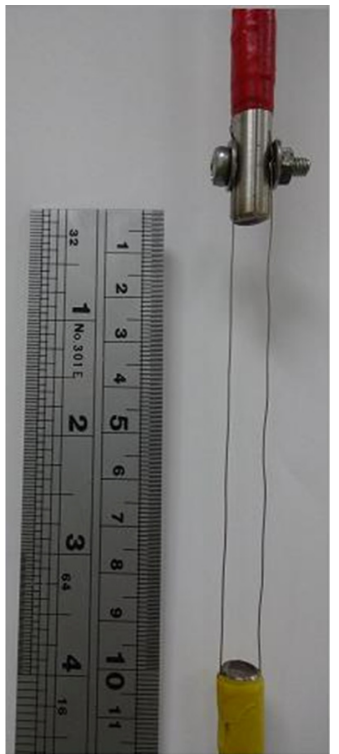

Fig. 3. The developed suspension wire.

parts as shown in Figure 2; the higher part (left side column, right side column both of a diameter $6 \mathrm{~mm}$ and length $700 \mathrm{~mm}$, double sheet mechanism and $6 \mathrm{~mm}$ diameter stainless steel rod) is to be operated above the distilled water surface and only affected by the air buoyancy. The lower part (left side column, right side column both of a diameter $6 \mathrm{~mm}$ and length $400 \mathrm{~mm}$, double sheet mechanism and pentagon shape position) is to be immersed below the distilled water surface and only affected by the liquid buoyancy. The two parts connected to each other with four stainless steel suspension wires with a diameter of $0.3 \mathrm{~mm}$ for each one and length of $100 \mathrm{~mm}$ as shown in Figure 3. The previous design of the weighing pan is shown in Figure 4 and its suspension wire with a diameter of $4 \mathrm{~mm}$ is shown in Figure 5 .

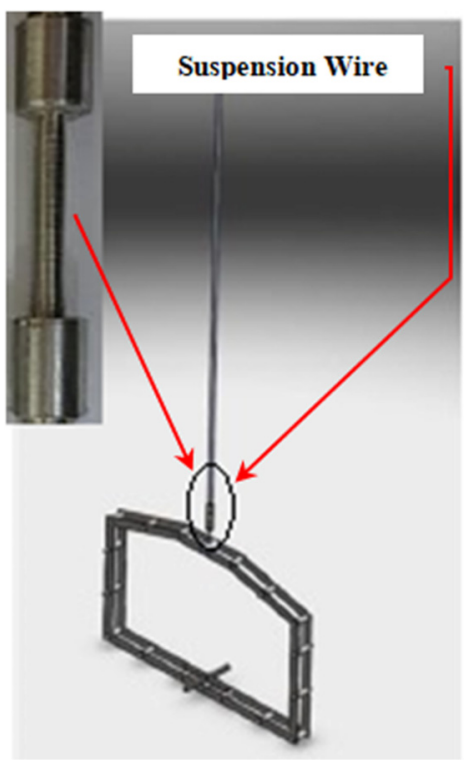

Fig. 4. previous weighing pan.

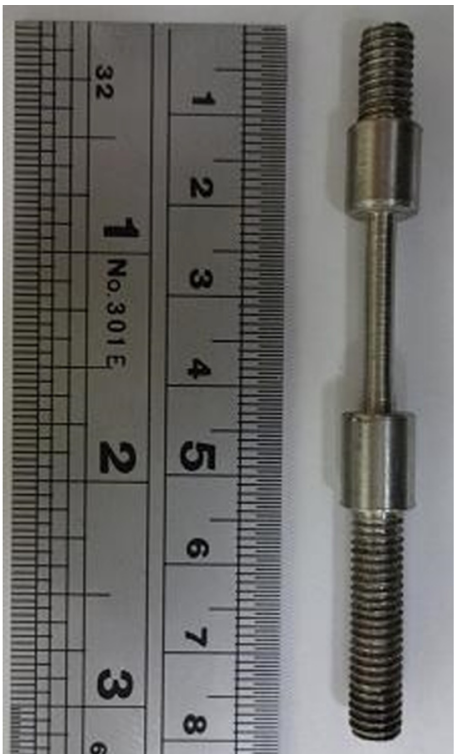

Fig. 5. The previous suspension wire.

All the component of the developed weighing pan are manufactured using stainless steel material 304 [15]. Solid works software at 3D and its FEM analysis are used to check the stresses and the deformation of the developed weighing pan. The maximum Von Mises stress was 137.3 MPa shown in Figure 6 with safety factor 1.5. The value of the maximum deformation was checked with $0.72 \mathrm{~mm}$ under a load of $20 \mathrm{~kg}$ as shown in Figure 7 .

\subsection{The developed 4-Positions Mass Handler}

The mass handler in the previous (HWA-NIS) shown in Figure 8 was designed with two positions for masses up to $10 \mathrm{~kg}$. The developed 4-positions masses handler was 


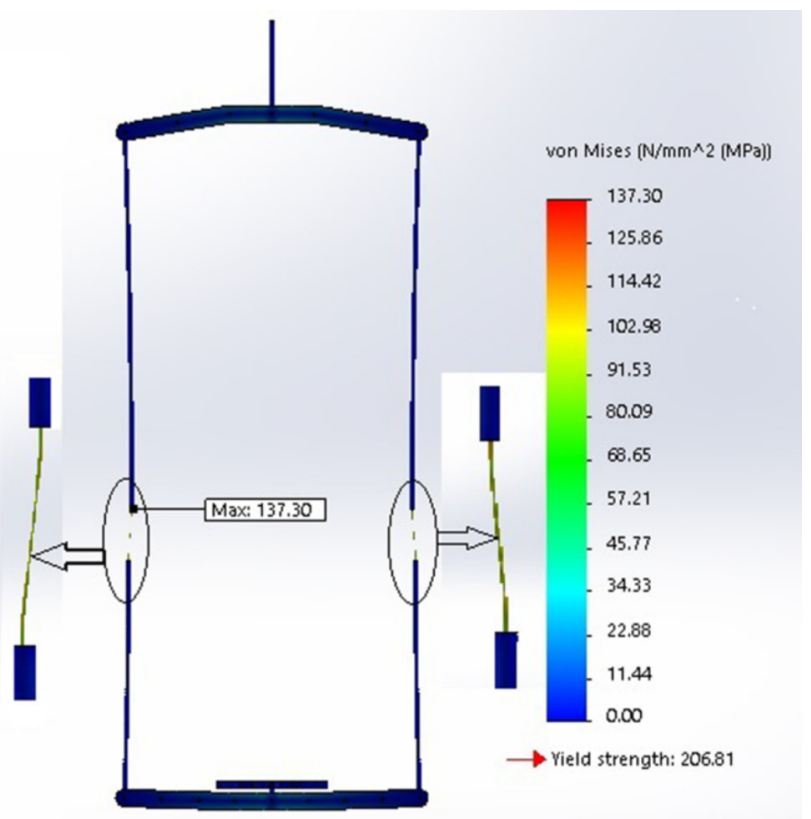

Fig. 6. The Von Misses stress distribution for the developed weighing pan.

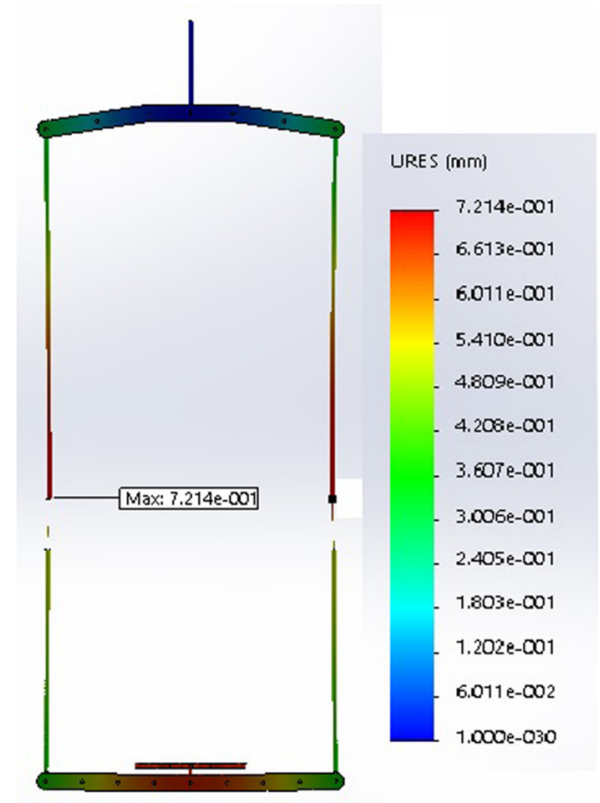

Fig. 7. The deformation distribution for the developed weighing pan.

designed with 4-position of pentagon shape as illustrated in Figure 9. It can carry four masses with a maximum capacity of $20 \mathrm{~kg}$ for each as shown in Figure 10. Each position was designed with a pentagonal shape to be able to carry groups of individual masses at once as shown in Figure 11 at the time of the density scale weighing process.

The 4-Positions mass handler was manufactured using stainless steel material 304 [15] with a diameter of $500 \mathrm{~mm}$ and thickness of $10 \mathrm{~mm}$. Solid works software at 3D and its FEM analysis are used to check the stresses and

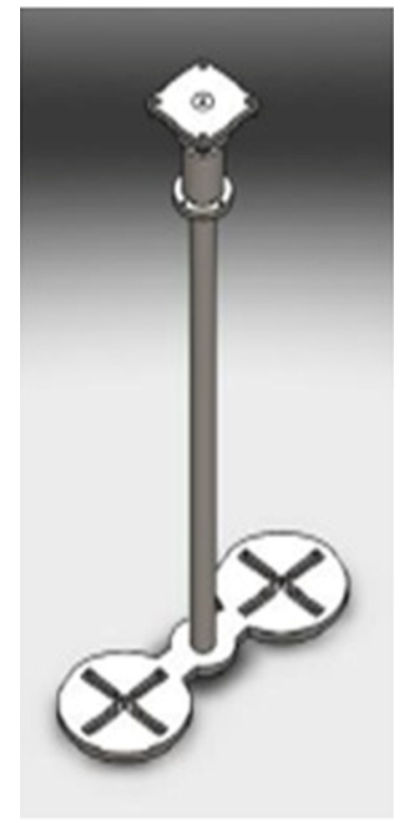

Fig. 8. The previous 2-positions mass handler.

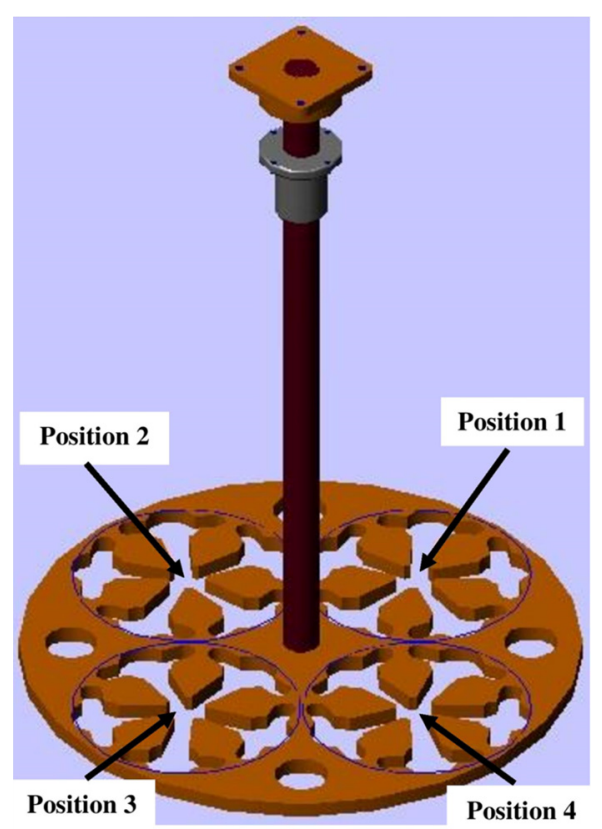

Fig. 9. The developed 4-positions mass handler.

deformation. The maximum Von Mises stress was $13.5 \mathrm{MPa}$ as shown in Figure 12 . The value of the deformation was checked with a calculated maximum value of $0.06 \mathrm{~mm}$ in the vertical direction under a load of $20 \mathrm{~kg}$ at each position as shown in Figure 13.

\section{Experimental work}

The density, volume and uncertainty calculations were performed according to the most accurate method $\left(\mathrm{A}_{2}\right)$ in 


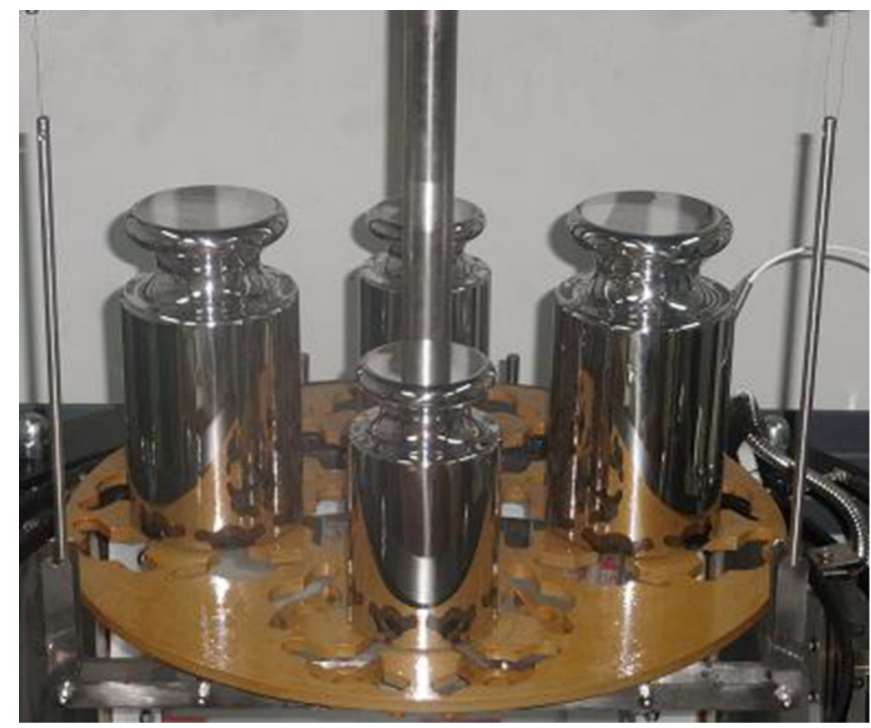

Fig. 10. A photograph for the 4-Positions Mass Handler.

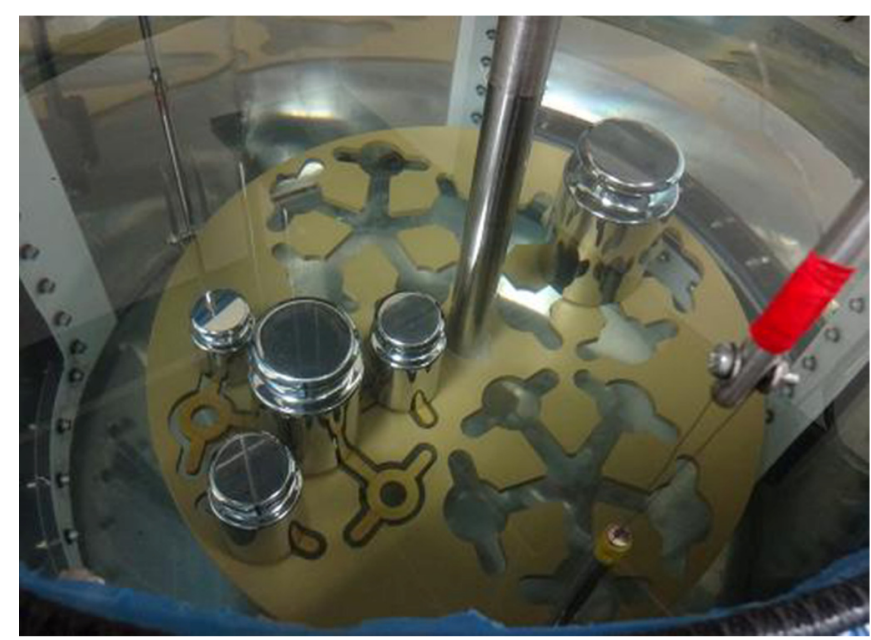

Fig. 11. The Mass Handler carries individual masses.

OIML R 111-1 standard [1]. The hydrostatic technique was used for relating the mass of the under calibration to the mass of the reference mass used both in air and in the reference liquid (distilled water) of known density [14] under nearly the same environmental condition. The distilled water was selected, as its density is a well-known function of temperature and it is low cost. The uncertainties less than $0.1 \mathrm{~kg} / \mathrm{m}^{3}$ would be reached through this method.

Before starting the weighing, The under test mass was placed on its associated positions on the 4-positions mass handler against the standard mass in the distilled water for about 8 hours to reach thermal stabilization. Five preweighing were carried out before starting the weighing comparisons for making a centering to the standard mass and the under test mass on the weighing pan. Five Reference-Test-Reference (RTR) cycles were performed. The balance reading was taken at the time of weighing via LabVIEW software after stabilization time.

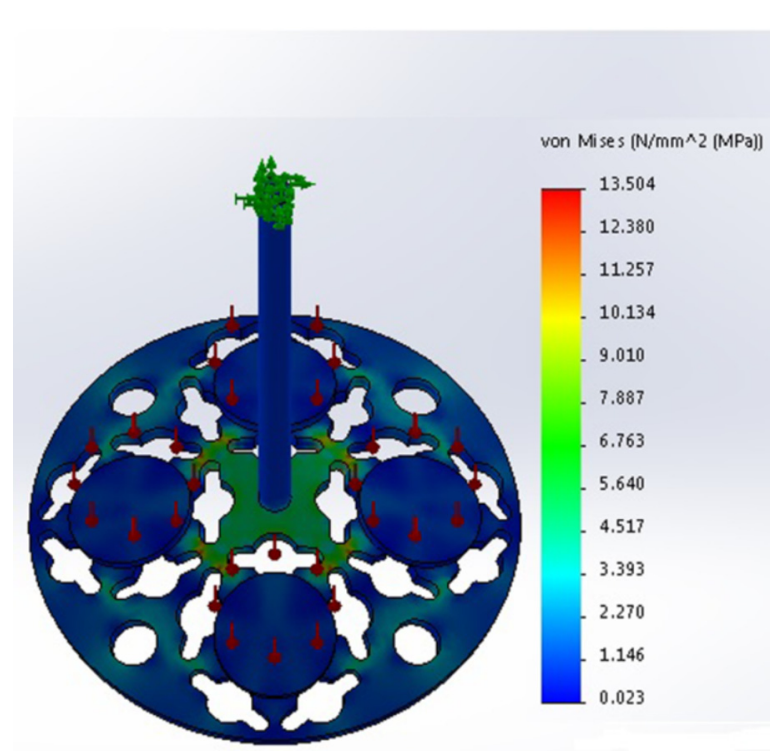

Fig. 12. The Von Misses stress distribution for the 4-Position Mass Handler.

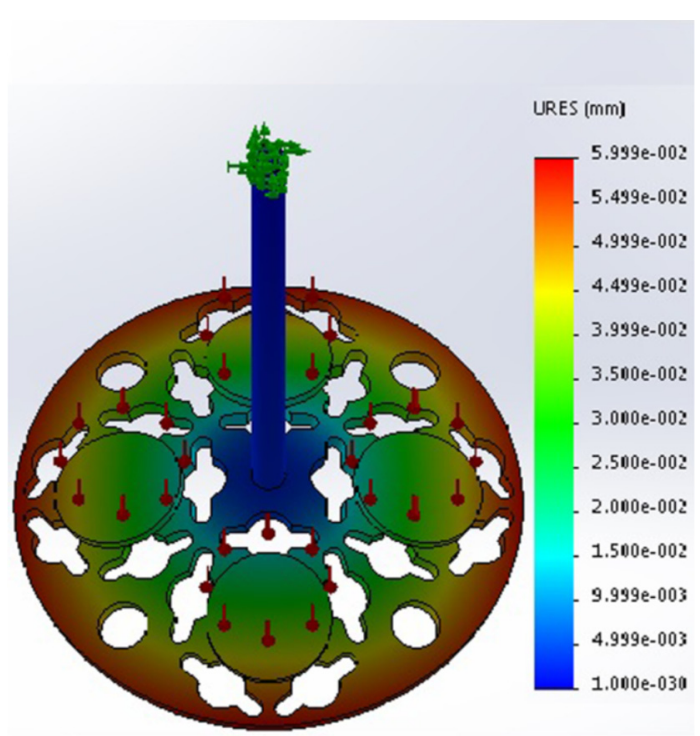

Fig. 13. The maximum deformation for the 4-Position Mass Handler.

\subsection{Measurement procedure}

- Weighing the reference mass $\left(m_{\mathrm{ra}}\right)$ in the air of density $\left(\rho_{\mathrm{a}}\right)$ and record the balance reading $\left(R_{\mathrm{ra}}\right)$.

- Weighing the mass under calibration $\left(m_{\mathrm{ca}}\right)$ in the air of density $\left(\rho_{\mathrm{a}}\right)$ and record the balance reading $\left(R_{\mathrm{ca}}\right)$.

- Weighing the reference mass $\left(m_{\mathrm{rl}}\right)$ under the surface of the distilled water of density $\left(\rho_{\mathrm{l}}\right)$ and record the balance reading $\left(R_{\mathrm{rl}}\right)$.

- Weighing the mass under calibration $\left(m_{\mathrm{cl}}\right)$ under the surface of the distilled water of density $\left(\rho_{1}\right)$ and record the balance reading $\left(R_{\mathrm{cl}}\right)$.

- Measure the temperature of the distilled water at the weighing readings $\left(R_{\mathrm{rl}}\right.$ and $\left.R c_{\mathrm{l}}\right)$. 


\subsection{Calculations}

- The density of the mass under calibration $\left(\rho_{t}\right)$ is then calculated using equation (1)

$$
\rho_{t}=\frac{\rho_{l}\left(C_{a} m_{r}+\Delta m_{w a}\right)-\rho_{a}\left(C_{l} m_{r}+\Delta m_{w l}\right)}{m_{r} \frac{\rho_{l}-\rho_{a}}{\rho_{r}}+\Delta m_{w a}-\Delta m_{w l}}
$$

where $\mathrm{C}_{\mathrm{a}}, \mathrm{C}_{1}$ are the corrections factors for the buoyancy force, can be calculated using the equations (2 and 3$)$ :

$$
\begin{gathered}
C_{a}=1-\frac{\rho_{a}}{\rho_{r}} \\
C_{l}=1-\frac{\rho_{l}}{\rho_{r}}
\end{gathered}
$$

$\Delta m_{w a}$ : the different between the weighing of the reference mass and the mass under calibration in air and can be calculated using equation (4),

$$
\Delta m_{w a}=\left(R_{c a}-R_{r a}\right) C_{s}
$$

$\Delta m_{w l}$ : The different between the weighing of the reference mass and the mass under calibration in the liquid and can be calculated using equation (5).

$$
\Delta m_{w l}=\left(R_{c l}-R_{r l}\right) C_{s}
$$

$\mathrm{C}_{\mathrm{S}}$ is the buoyancy force correction factor, can be calculated using equation (6):

$$
C s=1-\frac{\rho_{a s}}{\rho_{s}}
$$

where $\rho s$ : Density of the sensitivity mass, $\rho_{\text {as }}$ : Air density during calibration of the used balance.

The subscripts $a, l, r, c$ and $w$ were for air, liquid, reference mass, mass under calibration and weighing process respectively.

- The density of the mass under calibration $\left(\rho_{t}\right)$ can be calculated at reference temperature $20{ }^{\circ} \mathrm{C}$ from equation (7) as following:

$$
\rho_{t}\left(t_{r}\right)=\rho_{t} \times\left[1+\gamma\left(t-t_{r}\right)\right]
$$

where:

$\gamma$ : the coefficient of thermal expansion for the mass under calibration $\left(4.8 \times 10^{-5} \mathrm{C}^{-1}\right)$,

$t$ : the test temperature,

$t_{r e f}$ : the reference temperature $\left(20^{\circ} \mathrm{C}\right)$.

\subsection{Uncertainty sources evaluation}

The uncertainty sources were evaluated based on the method $\left(\mathrm{A}_{2}\right)$ in OIML R111 [1]. Type A and type B uncertainty components and evaluation were calculated according to the GUM standard [16].

Type A uncertainty components and evaluation:

Repeatability $\left(u_{\mathrm{rep}}\right)$ in the unit of $\left(\mathrm{g} / \mathrm{cm}^{3}\right)$ :

Is the standard deviation of successive density measurements of an under calibration mass carried out under the same conditions of measurement, divided by the number of measurements and can be obtained from equation (8).

$$
u_{\text {rep. }}=\frac{s}{\sqrt{n}}
$$

where $s$ : is the standard deviation, $n$ : is the number of measurements.

The repeatability has a normal probability distribution with a divisor $=1$ and sensitivity coefficient $(C i)=1$.

Type B uncertainty components and evaluation:

- The uncertainty in measuring the density distilled water $u(\rho l)$ in $\mathrm{g} / \mathrm{cm}^{3}$

- The uncertainty in measuring the density of reference mass $u(\rho r)$ in $\mathrm{g} / \mathrm{cm}^{3}$

- The uncertainty in measuring the mass value of the reference mass $u\left(m_{r}\right)$ in $\mathrm{g}$

- The uncertainty due to the weighing difference in distilled water between reference mass and under calibration mass $u\left(\Delta m_{w l}\right)$ in $\mathrm{g}$

- The uncertainty due to the surface tension effect $u\left(m_{\text {cap }}\right)$ ing

The probability distributions of the uncertainty components ( 1 and 2 ) are normal distributions with divisors $=1$ while the probability distributions of the uncertainty components $(3,4$ and 5$)$ are rectangular distributions with divisors $=\sqrt{3}$.

The sensitivity coefficients $\left(C_{i}\right)$ of the uncertainty components ( 1 and 2 ) are equal to 1 while the sensitivity coefficients $\left(C_{i}\right)$ of the uncertainty components $(3,4$ and 5$)$ are obtained from the partial derivative of the mathematical model presented in equation (1).

Combined standard uncertainty uc $(\rho \mathrm{t})$ :

Is obtained using the individual standard measurement uncertainties associated with the input quantities in the mathematical model shown in equation (1) and can be calculated using equation (9)

$$
\text { See equation (9) below. }
$$

Expanded uncertainty $\mathrm{U}(\rho \mathrm{t})$ :

Represent the product of the combined standard measurement uncertainty and a coverage factor $k=2$ at a confidence level of $95 \%$ which can be calculated from equation (10)

$$
U\left(\rho_{t}\right)=2 \times u\left(\rho_{t}\right)
$$

\section{Results and discussion}

The density and volume of four masses with nominal values of $2 \mathrm{~kg}, 5 \mathrm{~kg}, 10 \mathrm{~kg}$ and $20 \mathrm{~kg}$ were calculated using

$$
u_{c}\left(\rho_{t}\right)=\sqrt{\left(u_{r e p}\right)^{2}+\left(u\left(\rho_{l}\right)\right)^{2}+\left(u\left(\rho_{r}\right)\right)^{2}+\left(\frac{\delta \rho_{t}}{\delta m_{r}} u\left(m_{r}\right)\right)^{2}+\left(\frac{\delta \rho_{t}}{\delta \Delta m_{w l}} u\left(\Delta m_{w l}\right)\right)^{2}+\left(\frac{\delta \rho_{t}}{\delta \Delta m_{w l}} u\left(m_{\text {cap }}\right)\right)^{2}}
$$


the developed Hydrostatic Weighing System (DHWS-NIS). Table 1 illustrates the obtained results for the density and the volume as well as their corresponding expanded uncertainty values that were corrected to $20{ }^{\circ} \mathrm{C}$.

Figure 14 demonstrates the relation between the surface tension uncertainty percentage and the nominal mass. It was being seen that the developed weighing pan reduced the surface tension effect with about four times than the previous weighing pan. For the $2 \mathrm{~kg}, 5 \mathrm{~kg}, 10 \mathrm{~kg}$ and $20 \mathrm{~kg}$ masses, the previous values for the surface tension uncertainty percentage were $69.0 \%, 48.0 \%, 31.0 \%$ and $19.0 \%$ have been improved to $18.5 \%, 12.0 \%, 6.8 \%$ and $3.6 \%$ respectively and observed that its values decreased by increasing the nominal mass values.

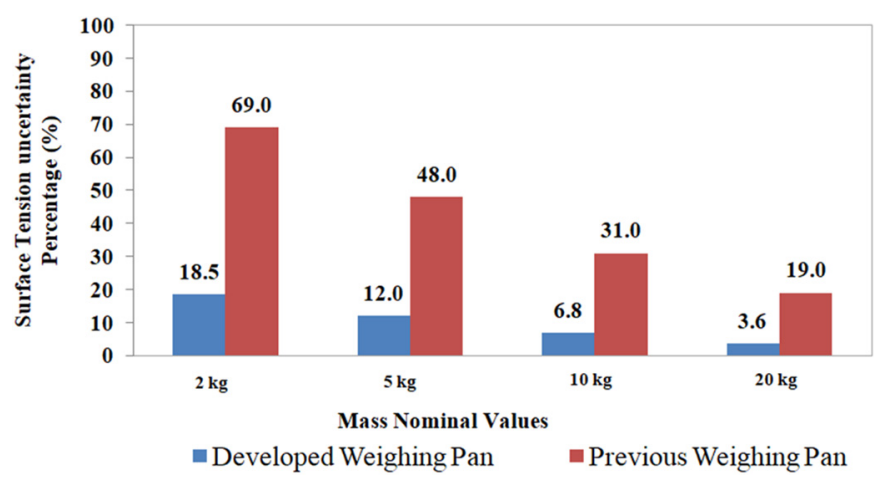

Fig. 14. The surface tension uncertainty percentage contribution for the masses from $2 \mathrm{~kg}$ up to $20 \mathrm{~kg}$.

Table 1. the density, volume and their associated uncertainties values obtained for the masses from $2 \mathrm{~kg}$ to $20 \mathrm{~kg}$.

\begin{tabular}{lllll}
\hline $\begin{array}{l}\text { Nominal } \\
\text { mass }(\mathrm{kg})\end{array}$ & $\begin{array}{l}\text { Density } \\
\left(\mathrm{g} / \mathrm{cm}^{3}\right)\end{array}$ & $\begin{array}{l}\text { Uncertainty } \\
@ k=2\left(\mathrm{~g} / \mathrm{cm}^{3}\right)\end{array}$ & $\begin{array}{l}\text { Volume } \\
\left(\mathrm{cm}^{3}\right)\end{array}$ & $\begin{array}{l}\text { Uncertainty } \\
@ k=2\left(\mathrm{~cm}^{3}\right)\end{array}$ \\
\hline 2 & 8.008641 & \pm 0.000149 & 249.730194 & \pm 0.000019 \\
5 & 8.004320 & \pm 0.000092 & 624.663155 & \pm 0.000011 \\
10 & 7.999941 & \pm 0.000081 & 1250.009276 & \pm 0.000010 \\
20 & 8.004601 & \pm 0.000078 & 2498.564852 & \pm 0.000010 \\
\hline
\end{tabular}

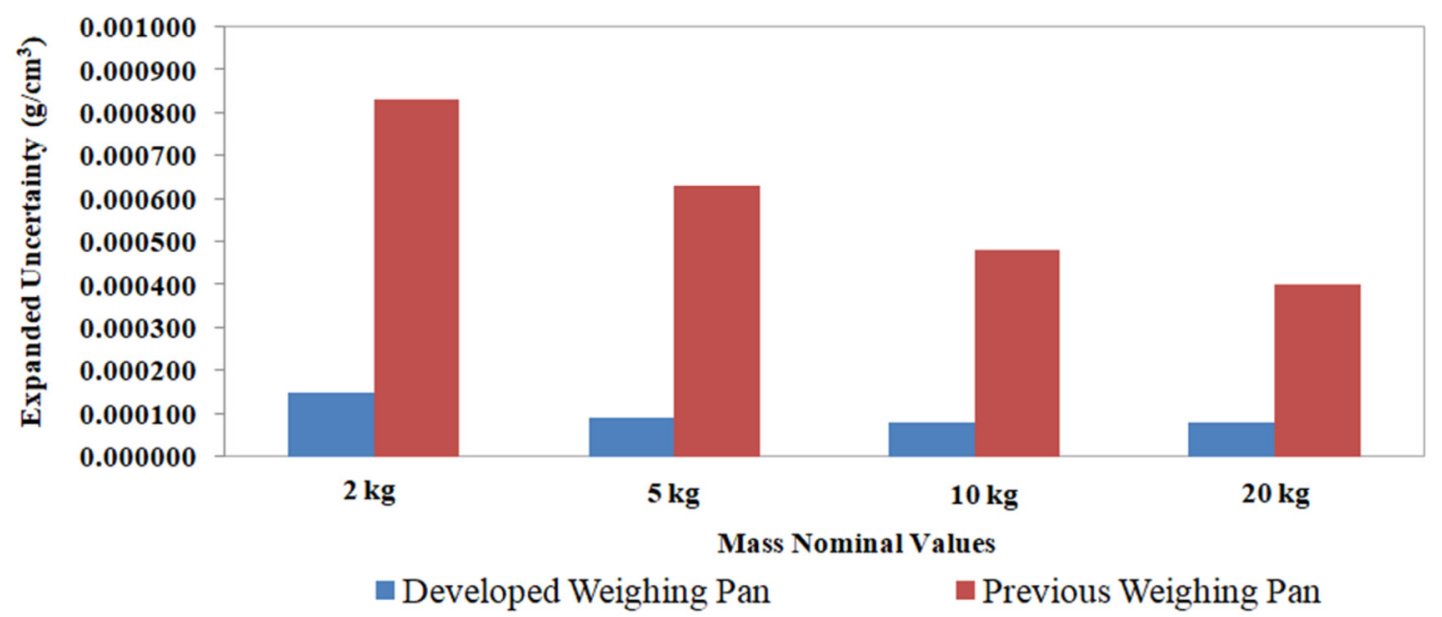

Fig. 15. The improved expanded uncertainty between the recent and previous results.
Figure 15 shows the relation between the nominal mass against a comparison for the expanded uncertainty obtained from using the developed weighing pan and the expanded uncertainty obtained from the previous weighing pan [10] in the masses from $2 \mathrm{~kg}$ up to $20 \mathrm{~kg}$. The expanded uncertainties were $0.00083 \mathrm{~g} / \mathrm{cm}^{3}$, $0.00063 \mathrm{~g} / \mathrm{cm}^{3}, 0.00048 \mathrm{~g} / \mathrm{cm}^{3}$ and $0.00040 \mathrm{~g} / \mathrm{cm}^{3}$ in the masses of $2 \mathrm{~kg}, 5 \mathrm{~kg}, 10 \mathrm{~kg}$ and $20 \mathrm{~kg}$ respectively [10]. These uncertainties were improved by about five times and became $0.000149 \mathrm{~g} / \mathrm{cm}^{3}, 0.000092 \mathrm{~g} / \mathrm{cm}^{3}, 0.000081 \mathrm{~g} / \mathrm{cm}^{3}$ and $0.000078 \mathrm{~g} / \mathrm{cm}^{3}$ in the masses of $2 \mathrm{~kg}, 5 \mathrm{~kg}, 10 \mathrm{~kg}$ and $20 \mathrm{~kg}$ respectively due to improve the measurement performance and reducing the effect of surface tension via the developed design of the weighing pan.

The previous NIS Hydrostatic Weighing Apparatus (HWA-NIS) up to $10 \mathrm{~kg}$ was developed for measuring the density of the masses ranging from $2 \mathrm{~kg}$ up to $20 \mathrm{~kg}$. A new immersion weighing pan was developed using four suspension wires with a diameter of $0.3 \mathrm{~mm}$ for each to reduce the surface tension uncertainty source effect by four times its initial value. The mass handler was developed with 4-positions of pentagon shape to be able to make handling for individual masses in a group at once, when transferring the traceability from the primary standard "the Silicon Sphere" to the standard masses in the density scale weighing process. The NIS Developed Hydrostatic

\section{Conclusion}


Weighing System (DHWS-NIS) was used to determine the density of four masses with nominal values of $2 \mathrm{~kg}, 5 \mathrm{~kg}$, $10 \mathrm{~kg}$ and $20 \mathrm{~kg}$ with improved expanded uncertainty of $0.149 \mathrm{~kg} / \mathrm{m}^{3}, 0.092 \mathrm{~kg} / \mathrm{m}^{3}, 0.081 \mathrm{~kg} / \mathrm{m}^{3}$ and $0.078 \mathrm{~kg} / \mathrm{m}^{3}$ respectively. This expanded uncertainty was improved by about five timed from its initial value due to reducing the effect of surface tension via the developed design.

\section{References}

1. International Organization of Legal Metrology (OIML) R 111-1, 1-77 (2004)

2. C. Buchner, Automatic testing facility for determining liquids and solids density; and determining the volume of $\mathrm{E}_{1}$ weights, in 20th IMEKO TC3 Int. Conf. Meas. Force, Mass Torque, 2007

3. S.V. Gupta, Practical Density Mesurement and Hydrometery (British Library Cataloguing, 2002)

4. M. Thiesen, T. A. M. International Bureau of Weights and Measures, 1975

5. H.A. Bowman, R.M. Schoonover, J. Res. Natl. Bur. Stand. Sect. C Eng. Instrum. 71C, 179 (1967)

6. Federal Institute of Metrology (METAS), Precise Determination of Volume and Density of Solid Bodies, 1-2 (2012)
7. C. Buchner, Development and realisation of a fully automatic testing facility for determining the volume of E1 weights up to $50 \mathrm{~kg}$ based on hydrostaticweighing, in 19th IMEKO World Congress 2009 (2009), vol. 1, pp. 182-185

8. Y.J. Lee, W.G. Lee, M. Abdurahman, K.P. Kim, Density mesurement system for weights of $1 \mathrm{~kg}$ to $20 \mathrm{~kg}$ using hydrostatic weighing, Int. J. Mod. Phys. Conf. Ser. 24, 1360026-1 to $1360026-6$ (2013)

9. B.M. Sayed, B.S. Azzam, M.Z. Abdou, A.A. Eltawil, Adv. Mater. Res. 909, 127-134 (2014)

10. B.M. Sayed, A.B.S. Azzam, B.M.Z. Abdou, A.A. Eltawil, Design, control and optimization of the weighing mechanism for the HWA-NIS up to $20 \mathrm{~kg}$, in Proc. - 2016 3rd Int. Conf. Inf. Sci. Control Eng. ICISCE 2016, 2016, pp. 302-307

11. G. Richard, Budynas, J. Keith Nisbett, Mech. Eng. Des. (2011)

12. M.H. Mohamed, M.A. Bayoumi, A.A. Eltawil, A.E. Abuelezz, Int. J. Innov. Res. Sci. Eng. Technol. 3, 12735-12741 (2014)

13. A. Picard, R.S. Davis, M. Gläser, K. Fujii, Metrologia 45, 149-155 (2008)

14. M. Tanaka, G. Girard, R. Davis, A. Peuto, N. Bignell, Metrologia 38, 301-309 (2001)

15. J.E. Bringas, Handbook of comparative world steel standards (ASTM DS67B). Library of Congress Cataloging (2004)

16. S. Bell, 'A Beginner's Guide to Uncertainty of Measurement' (National Physical Laboratory, 2001)

Cite this article as: Mohamed Hamdy, Mohamed A. Bayoumi, Ali E. Abuelezz, Alaaeldin A. Eltawil, Developing the NIS solid density hydrostatic weighing system up to $20 \mathrm{~kg}$, Int. J. Metrol. Qual. Eng. 11, 8 (2020) 